MARK D. GRIFFITHS ${ }^{1}$

ANDREA M. LEWIS ${ }^{2}$

ANGELICA B. ORTIZ DE GORTARI ${ }^{3}$

DARIA J. KUSS ${ }^{4}$

Nottingham Trent University, United Kingdom

\title{
ONLINE FORUMS AND SOLICITED BLOGS: INNOVATIVE METHODOLOGIES FOR ONLINE GAMING DATA COLLECTION
}

\begin{abstract}
Although online data collection has become increasingly common for social scientists working in the field of gaming studies, two of the least used methods in online gaming research are the collection of data from (i) online forums and (ii) solicited online diary blogs. This paper overviews these two innovative data collection methods and examines both the advantages (e.g., ease of data collection; rich and complex resource of textual material that can be revisited after the event; targeting specific and/or diverse populations; participant anonymity; participant convenience; increased honesty, etc.) and disadvantages (e.g., lack of contextual data; sampling bias; lack of researcher control, lack of knowledge about participant behaviour, generalizability) to aid those researchers working in the online gaming studies field. This paper extends upon previous methodological papers in the area by outlining some of the methodological and ethical issues associated with these two specific online methodologies. Although online data collection may raise concerns about the research participants' integrity and the quality of the data collected, it is concluded that the use of online forums and online solicited diary blogging can provide new insights unavailable to other data collection methods for those working in the gaming studies field.
\end{abstract}

Keywords: Online gaming, Online data collection, Online methodologies, Online forums, Online diary blogs

1 Correspondence address: mark.griffiths@ntu.ac.uk

2 Correspondence address: helloandrea@gmail.com

3 Correspondence address: angelica.ortizdegortari@gametransferphenomena.com

4 Correspondence address: daria.kuss@ntu.ac.uk 


\section{FORA I BLOGI INTERNETOWE JAKO INNOWACYJNE METODY BADAŃ W OBSZARZE GIER ONLINE}

\section{STRESZCZENIE}

Badania prowadzone przez internet na temat gier online i ich użytkowników stają się coraz bardziej powszechne. Jednak naukowcy nadal rzadko wykorzystują dwa sposoby zbierania wyników, tj. (i) fora internetowe oraz (ii) prywatne blogi. Celem artykułu jest omówienie tych dwóch, niezbyt powszechnie znanych, metod zbierania danych i analiza zarówno zalet (np. łatwość zbierania danych, źródło różnorodnego i złożonego materiału tekstowego, które może być wykorzystane do analizy konkretnych zdarzeń, docieranie do specyficznych i/lub zróżnicowanych grup badawczych, zapewnienie anonimowości uczestnikom badania, nieobciążanie badanych, większy poziom szczerości itp.), jak i wad (np. brak informacji o warunkach badania, błędy w doborze prób badawczych, brak kontroli warunków badania przez badacza, brak wiedzy na temat zachowań uczestników badania, brak uogólnionych wyników). Artykuł może być pomocny dla tych naukowców, którzy prowadzą badania w obszarze gier online. Poszerza on zakres wcześniejszych prac, przedstawiając metodologiczne i etyczne problemy związane z wykorzystaniem forów i blogów w naukach społecznych. Mimo że prowadzenie badań za pośrednictwem Sieci może budzić obawy zarówno w odniesieniu do rzetelności, jak i do jakości zebranych wyników, to wykorzystanie i analiza treści zaczerpniętych z forów i blogów może dostarczyć nowych, cennych informacji. Zazwyczaj są one niemożliwe do pozyskania drogą innych metod badawczych stosowanych w analizie gier online i badaniu ich użytkowników.

Słowa kluczowe: gry online, metodologia prowadzenia badań online, fora i blogi internetowe

\section{INTRODUCTION}

Online data collection is a methodological phenomenon that is becoming a focus of interest for an increasing number of researchers in the scientific community. The Internet offers potentially new and interesting opportunities to collect data and it has democratised data collection (Kraut, Olson, Banaji, et al., 2004). More specifically, researchers in the social sciences are starting to use online methods to gather their data, rather than using traditional offline research approaches (Griffiths, 2010; Wood \& Griffiths, 2007). One area that has seen a substantial growth in research over the last decade is in the online gaming studies field (including both online gambling and online video game playing).

Psychological research into online gaming that can be done on the Internet includes correlational, cross-sectional, experimental, self-report, and/or observational research. A recent methodological review paper by Griffiths (2010) examined seven different online data collection methods that he had personally used for collecting data from gamblers and gamers including (i) online questionnaires, (ii) online forums, (iii) online participant observation, (iv) online 
secondary data, (v) online interviews, (vi) online exemplar websites, and (vii) online evaluations (including online 'mystery shopping'). He also argued in the same paper that the Internet can be a very useful medium for eliciting rich and detailed data in sensitive research areas such as gaming addictions. Two of the least used methods in online gaming research are the collection of data from (i) online forums and (ii) solicited online diary blogs.

Based on the authors' online research expertise, this paper overviews these innovative data collection methods examining both its advantages and disadvantages to aid those researchers working in the online gaming studies field. Although there has been a lot of methodological attention devoted to blogs and forums by educators, linguists, sociologists, it has been relatively unexplored by social scientists and psychologists in the gaming studies field. Therefore, it is argued that researchers in the gaming studies field would benefit by considering these two newer methods of online data collection in combination with more 'traditional' online data collection methods (e.g., online surveys, online interviews, online participant and nonparticipant observation, etc.).

\section{THE CASE FOR ONLINE DATA COLLECTION}

There are a number of reasons why the online medium is a good place to conduct social science research onto online gaming. This is because the Internet: (i) is usually accessible to many (and specific) target populations (such as online gamblers and online video game players), and such groups are usually proficient in using it (Wood \& Griffiths, 2007); (ii) allows for studies to be administered to potentially large scale samples quickly and efficiently (Buchanan, 2000, 2007; Wood, Griffiths, \& Eatough, 2004); (iii) can facilitate automated data inputting allowing large scale samples to be administered at a fraction of the cost and time of 'pen and paper' equivalents (Buchanan, 2007); (iv) has a disinhibiting effect on users and reduces social desirability, leading to increased levels of honesty (and therefore higher validity in the case of self-reports) (Joinson, Paine, Buchanan, \& Reips, 2008); (v) has a potentially global pool of participants, therefore researchers are able to study extreme and uncommon behaviours (such as gambling addiction) as well as make cross-cultural comparisons (Buchanan, 2000); (vi) provides access to "socially unskilled" individuals who may not have taken part in the research if it was offline because of social awkwardness and inhibition (Wood et al., 2004; Wood \& Griffiths, 2007); (vii) can aid targeted participant recruitment through advertising on various and specific (e.g., gaming) bulletin boards and websites (Wysocki, 1998); (viii) can aid researchers because they do not have to be in the same geographical location as either the participants or fellow research colleagues (e.g., Whitty, 2004a; Wood et al., 2004); and (ix) can facilitate long-term research where participants interchange information in a rich variety of formats such as text, images, sound or video (Kraut et al., 2004). 
Despite these many advantages of online (over offline) data collection, there are a number of specific issues that researchers who collect gaming data in online media - particularly with regards to online self-report methods - need to be aware of. For instance, in the early days of online research, there was the concern that data collected via online means might not be valid (e.g., Davies, 1999). Some of the main disadvantages of online methodologies (such as sampling bias, selfselected samples, issues concerning reliability and validity) are also encountered in more conventional offline research methodologies, although online methodologies may give rise to different types of problems when compared to traditional offline research (e.g., sampling bias where online populations may look very different from offline populations, lack of researcher control, lack of knowledge about participant behaviour, hardware/software variability) (Buchanan, 2007).

To be more precise, if researchers decide to do research using the Internet, they must be familiar with both the technology as well as the virtual environment that they use. First, researchers have to ensure that the web application they use (i.e., the respective forum or solicited blog) is accessible and allows users to act on and interact with it as well as with other users (Schmidt, 2007). Should the data gathered vary because of the way in which it has been collected (i.e., via the Internet) one speaks of 'technical variance' (Reips, 2002). There are a variety of reasons why technical variance can occur. They include the properties and settings of the user interface as well as the speed of the users' (and researcher's) broadband connection (Krantz, 2000). In addition to this, accessibility may be limited in case users need to become members of the respective forum or weblog in order to use the data provided. In such cases, it is indispensable to contact site administrators and moderators prior to data collection (Hine, 2005).

Secondly, only if the researchers are aware of the embedding of their data within the respective virtual realm, can they make sense of it (Hine, 2000). This topic is explored in more depth in the section on participant observation (below). In addition to this, the researchers must be aware of the potentially limited quality of data that they gather via the Internet. They need to specifically ensure the reliability of collected data especially if these data derive from online forums and solicited blogs. Data can be of poor quality, irrelevant and redundant, and it may stem from unreliable sources. In addition to this, data collected via these online environments can be utilized both quantitatively as well as qualitatively. There are a variety of approaches to be adopted in terms of data analysis. In order to ensure high academic standards for scientific publications, researchers are specifically advised to ensure inter-coder reliability. Because of this, online research should preferably occur in a research team rather than just one person (Jankowski \& van Selm, 2005).

In summary, forums and solicited blogs offer a wide variety of potentialities for researchers to assess manifold phenomena and they offer many advantages 
relative to offline research arenas and tools. As long as the researchers are aware of the potential pitfalls associated with using these online methods and assess their data critically with regards to the latter, working with online forums and solicited blogs appears as an innovative, efficient and expedient scientific approach to assess online phenomena (such as online gaming and online gambling) and beyond.

\section{DATA COLLECTION Via ONLINE FORUMS}

One of the reasons that online forums can be so useful to social science researchers is that they can potentially contain a rich and complex resource of textual material. This may include a person's experiences, perceptions, beliefs and feelings. Online forums typically include members and/or participants who share a particular hobby or interest (e.g., playing video games or gambling), disability (e.g., being deaf), and/or illness (e.g., breast cancer). For instance, the authors of this paper make particular use of gaming forums as a way of collecting data from players about very specific aspects such as 'addiction' (Chappell, Eatough, Davies, \& Griffiths, 2006) or particular experiences such as 'Game Transfer Phenomena' (Ortiz de Gortari, Aronsson, \& Griffiths, 2011).

\section{Advantages of online forums for data collection}

In general, the advantages of using online forums for gaming research lie in their (i) cost-efficiency, (ii) time-efficiency, (iii) widened scope for targeted data collection (i.e., regarding content and geographically dispersed samples), (iv) increased access to specific populations (due to their asynchronous nature) that are otherwise difficult to reach, (v) convenience and comfort of participation from home, and (vi) participant anonymity and consequent openness (Edmunds, 1999). The Internet allows users (such as gamers) to voice their opinion freely without being obstructed by potential physical, geographical and/or sociocultural factors that may otherwise hinder their participation in face-to-face discussion groups or one-to-one interviews. Participants typically feel free to discuss sensitive and personal topics, from menopausal symptom experience (Im, Liu, Dormire, \& Chee, 2008) through to gaming addiction (Chappell et al., 2006). This indicates that online forums potentially provide their agents with more perceived freedom than embodied situations could. Consequently, openness and willingness of disclosure may be higher in online forum discussion groups compared with face-to-face discussions.

Online forums also allow researchers to study interactions between forum members by observing and analyzing patterns of communication and online behaviours. Unlike traditional digital communication platforms such as email, forums allow for two-way and reactive communication between users such as gamers, or (more appropriately) agents in these virtual spheres. 
There are a number of factors that are significant for gaming researchers studying phenomena using online forum posts. First, they can expect a relatively homogenous group of agents interacting with one another (Schultz, 2000). Access to the Internet is a pre-requirement and therefore it cannot be disregarded that people who participate are actual Internet users, which already distinguishes them from the rest of the world population that has no access (Rezabek, 2000). Second, forums typically attract people sharing a common interest (such as gambling and video game playing) and therefore the topic of discussion is relatively contained. Third, forums are not only used as a knowledge base for people who want to share information about specific topics (such as problematic play), but they are also used as discursive tools. The possibility for vivid discourse in online forums breeds interactions that can be analyzed for scientific purposes (Schultz, 2000). It gives the researcher the possibility to get an in-depth insight into people's opinions, expectations, and motivations concerning the phenomena (e.g., gaming) under study. Likewise, it allows for investigation of the dynamics of public discussions and opinion forming. In this respect, using online forums for research purposes may aid gaming researchers and practitioners from a wide variety of natural and social science subjects in their research, including psychologists, physicians, sociologists and political scientists.

There are also considerations around incentives for online populations to participate in the research process. Previous experience in recruiting young video game players in online forums by the third author suggests that offering some type of incentive is recommended. She observed that when gaming forum participants were offered a reward (e.g., movie tickets), the participants were more willing to show an interest in participation. However, she also noticed that some video game players only took part in the study so that they could get the reward on offer, and tended to provide limited information in comparison to those players who were intrinsically motivated to participate in the first place without a reward necessarily being offered.

\section{Challenges for researchers collecting online forum data}

Given the potentially never-ending source of data found in online forums (such as gaming forums), another challenge when collecting data in such a medium is deciding when to stop data collection. For this reason it is important for the researcher to set pre-defined variable boundaries in terms of both time and data collected. Some of the other limitations in online forum data collection are potential misinterpretation of the words and sentences used by the participants. Because the researchers do not always have total access to the complete communication between participants, data analysis can sometimes occur without knowing the full context. For instance, posts may have been deleted and/or communication between participants may have taken place in other arenas such as private emails (Sixsmith \& Murray, 2001) or social networking sites. 
In their study of cancer pain experience, Im and Chee (2006) found that using online forums as qualitative research method offered five issues that researchers in any area (including those in the gaming studies field) should be aware of in relation to data collection from online forums.

- Researchers should be aware that the credibility of data (i.e., the truthfulness) gathered through online forums is supported because this method typically results in high response rates, high retention rates, and instantly transcribed data. However, they contend that researchers need to be aware that there are problems with theoretical sampling using online forums (i.e., there is no saturation possible), and this particular method only fits special research approaches.

- Researchers should be aware of the potential dependability of the sample under investigation, specifically concerning populations of mentally and/ or physically handicapped populations.

- Researchers must ensure that the language and jargon they use is clearly defined throughout their research. This is particularly important since online language has its own particular vocabulary. Furthermore, it relies exclusively on disembodied communication and may therefore be more difficult to interpret accurately (Crystal, 2005; Thurlow, 2001).

- Researchers should be aware that there may be issues concerning transferability of the generated data because online forum posts are particularly personal. However, this criticism not only applies to qualitative research using online forums, but to qualitative research in general. Moreover, generalizability in qualitative research cannot be equated with generalizability in quantitative research. What is essential is the fit between the data gathered and the population that is studied (Schofield, 1993).

- Researchers must be aware of potential security problems. These include protecting the participants' privacy, confidentiality of the data, integrity of data, authentication of user, and availability of data (Kinkus, 2002). The Internet changes every day because of new and updated content. Therefore, it is important to ensure that each one of the security domains that may potentially be endangered on the Internet is protected by the research team.

Wood and Griffiths (2007) - who specifically examined online gambling methodologies - note that online forum data are naturalistic and can be collected without identifying oneself as a researcher or even acknowledging a researcher's presence. Gaming forums are typically in the public domain, and no usernames or passwords are needed to access the sites. Furthermore, researchers do not need to participate in any online communications to elicit data. This form of Internet-based research approach has been described as both passive (Eysenbach \& Till, 2001) and unobtrusive (Paccagnella, 2006). The use of online forum data allows researchers to carry out in-depth examinations of how individuals 
perceive, experience, and make sense of the topic under investigation. Despite the clear advantages of using online forum data to study particular populations (e.g., ease of data collection, costefficiency), the collection of addiction data by 'lurking' (i.e., observing without making presence known) raises interesting ethical issues (Griffiths \& Whitty, 2010). These issues are discussed in more detail later in this paper.

In addition to this, Marra, Moore and Klimczak (2004) specified two protocols that can be used to comparatively analyse data qualitatively using online discussion forums. The first paradigm, the Interaction Analysis Model (IAM), is when data coding occurs in segments and it includes five phases. In the first phase, data are shared and compared. Next, inconsistencies in data are identified. In the third phase, meaning is negotiated, whereas in the fourth phase, the new knowledge is tested. Finally, agreements are synthesized. In sum, the IAM gives an in-depth insight into the dynamics of discourse and the production of knowledge (Marra et al., 2004).

Alternatively, the Newman scheme utilizes sentence coding where short codes are used prior to and following every sentence of gathered data. It is distinguished between agreements and disagreements between participants and a rationale is provided for labeling participants' statements as agreements or disagreements and cross-checked with the original code definitions until the point where there is a unitary agreement between raters as to whether a disagreement occurred within the participants' statements. Based on this coding scheme, researchers are able to discern critical thinking that is present among the agents within online discussion forums (Marra et al., 2004). The examples of IAM and the Newman scheme provide valuable tools for researchers who aim to use content analysis for investigating data from online discussion forums. These are specific qualitative research methods that can provide insights into very different phenomena to be investigated. On the one hand, knowledge production and distribution can be studied. On the other hand, critical thinking can become the focus of investigation. Depending on the researchers' aim, they are able to discern the appropriate methodological tool that fits their own research ambitions and requirements.

\section{Participant ObSERVATION IN ONLINE FORUMS}

In offline situations, many social science researchers have employed ethnographic methods as a means of understanding and describing different cultures. However, ethnographic methods can also be used online. Griffiths (2010) has argued that by being online, gaming researchers have the capacity to become a part of the phenomenon that is being studied. Ethnography focuses on accounting for the actions and intentions of the studied social agents, and outlining how such behaviour is rationalized and understood by the wider group (Ley, 
1988). Traditionally derived from anthropology, ethnography aims at studying people and their behaviours and cultures within their socio-cultural contexts. Behaviours and communications are engulfed with meaning by being situated within the field site. What is needed on behalf of the researcher is to produce a "thick description" of what takes place in these field sites to discern the latter's contextualized meaning (Geertz, 1973).

When it comes to virtual (i.e., online) ethnography, it is important to notice that while in-person ethnography is constrained by the laws of the physical world where the researcher needs to interact with the participants, online ethnography or as Kozinets (2010) calls it, "netnography" can be done in a more unobtrusive way without the need to interact with the participants. Lurking (discussed later in the paper) is a possibility that opens a "window into naturally occurring behaviour" without the interference of the researcher (Kozinets, 2010; p. 56).

Virtual ethnography takes the idea of participant observation a step further by challenging the notion of a geographically bound and relatively stagnant field site by replacing it with the virtual sphere that has no set boundaries. In this respect, virtual ethnography is "ethnography in, of and through the virtual" (Hine, 2000, p. 65). The Internet is used as place, topic and means of research. It is an important qualitative online methodology and has been used in a variety of different research endeavours, including the studies of people's explorations of multi-layered identities on the Internet (Turkle, 1995), different levels of online experience (Markham, 1998), and playing Massively Multiplayer Online Role-Playing Games such as Everquest (Taylor, 2006).

There are a number of principles that underlie virtual ethnography. Ethnographers must immerse themselves in the (virtual) field site in order to gain an in depth insight into why and how interactions take place and what they mean within the context of the respective virtual sphere. However, the relationship of the latter's agents to their real (embodied) lives cannot be disregarded. The online space is a space "in between" that is connected to the world outside of the Internet. Therefore, virtual ethnography is but a partial study and cannot deliver a full account of what it sets out to study. It can never be a holistic approach. Nevertheless, this is aided by the researchers who must be reflexive about what they experience, and about the method they use. The involvement of the researcher and the researcher's interpretation of the actions and communications that occur within the virtual field site are integral to this type of research. In addition to this, the technology of the Internet itself is essential because it provides the tools for, the objects and the context of analysis.

Given the wide variety of advantages of and important insights virtual ethnography can offer for the researcher, potential disadvantages also need to be taken into consideration. The researchers' active participation in the field site offers them the possibility of in-depth insights that would not be possible without their involvement. However, at the same time, they might lose their 
critical distance towards the object of their study. Sacrificing some critical distance therefore is a trade-off for the collection of invaluable and profound data. These data are necessarily biased by the researchers' experience and perception of online interactions in the respective realm that, due to their immersion, is knowledgeable and familiar (Hine, 2000).

Parke and Griffiths (2011) applied online ethnography to the study of poker skill development within online poker forums. The study used a virtual ethnographical research design looking at how poker gamblers utilize computer-mediated communication (CMC) to develop their poker skill and profitability, and to examine the factors associated with problem gambling. Their study comprised a six-month participant observational analysis of two independent online poker forums. One member of the research team participated in poker gambling during the entire study period and used strategies proposed from forum members to develop poker ability. This approach provided an insider's perspective into how skill development through CMC affects poker gambling behaviour.

The researchers generated forum discussions regarding specific behavioural concepts and cognitive processes based on accumulative analysis of emergent data. Forum interaction was observed, monitored and analyzed through traditional content analytic methods. Membership and participation in such online community forums provided poker players the opportunity to benefit from the consequences of reporting gambling experience and acquiring both poker gambling structural knowledge and skill.

One of the key advantages of data collection via online forums is that it can provide a detailed record of events that can be revisited after the event itself has finished. Furthermore, screen captures can be taken and used as examples or related back to the data collected - something that has been used in the gaming studies field (Wood \& Griffiths, 2007). Study findings can be posted on bulletin boards and study participants have the opportunity to comment on their accuracy or comment on any other observations that they may have. This also helps to empower the participant and can prevent misrepresentation.

\section{DATA COLLECTION VIA SOLICITED ONLINE DIARY BLOGGING}

Blog is a portmanteau of "web log" and refers to a popular method of self-publication on the World Wide Web that provides the writer/creator with a flexible and interactive platform for sharing content and interacting with potential readers (Herring, Scheidt, Bonus, \& Wright, 2005). Since 2004, Technorati. com, a blog search engine and directory, has published a report on the state of the blogosphere, collecting statistics on how frequently blogs are updated, categorising the general content and purpose of blogs, how they have evolved over time, their use of multimedia content (including photos, video, and audio), 
and the prevalence of blogging software used. In the most recent report from survey results of 7,205 bloggers from around the world, Technorati Media (2011) described blogs as a thriving ecosystem with bloggers updating their blogs more frequently than ever and spending more time blogging.

The report highlighted that the majority of respondents (60\%) were "hobbyist" bloggers and "blog for fun" or to express their "personal musings," with the main motivation being able to "speak their minds." In terms of research on the blogosphere from a social science perspective, Herring et al. (2006) conducted a longitudinal study of 457 blogs where they reviewed filter blogs that 'filter' information from other sources on the web such as news, personal journal blogs that functioned as online diaries, and knowledge-logs (k-logs) that focus on a highly specific topic or that are more technical in the orientation of content. The researchers gathered their sample of blogs randomly, excluding any blogs that focused on photo or audio sharing, and any blogs with less than two entries.

Accordingly, it has been found that the embedding of blogs within other sites, such as online social networking sites, does not have an impact on the ways blogs are used as personal diaries (Fullwood, 2009). Their results showed that although blogs can be used for many purposes and cross-purposes, the majority of blogs were singleauthored personal diaries and so blogs as a genre were mostly reflective of personal content. Furthermore, Serfaty (2004) categorised blogs as self-representational writing and positioned them as online diaries that, similar to traditional pen and paper diaries, are used to share personal thoughts and experiences, with the option of allowing others to read and comment on the entries. Social scientists have considered blogs in research, however, the methodology of such studies tends to focus on analysing or surveying the content of pre-existing blogs on the Internet (see Enoch \& Grossman, 2010; Hookway, 2008; Miura \& Yamashita, 2001; Kraut et al., 2004; Papacharissi, 2007) and often raises ethical issues around anonymity and awareness of self-disclosure (Kraut et al., 2004; Qian \& Scott, 2007).

A recent approach has been to use blogs as a methodological tool for qualitative research purposes. Kaun (2010) highlighted the challenges and benefits of using blogs and focused on the analysis of content from solicited online diaries or blogs in qualitative research versus that of non-solicited, pre-existing diaries published online. Kaun (2010) argued that solicited content should be analyzed differently because the topics are directed by the researcher and consciously controlled by the participant, who is aware the content will be used for analysis. However, Kaun (2010) goes on to argue that solicited diaries - whether online or offline - can be particularly useful when attempting to capture "subjective states and perceptions of participants" (p. 137).

Cohen et al. (2006) reported that online diaries were considered a useful tool in project implementation for qualitative evaluations in the education sector. In addition, blogs have been explored as a tool for learning in educational 
research (Williams \& Jacobs, 2004). Blogs have also been used as a successful method of data collection in public health studies. For example, Lim et al. (2010) evaluated the best platform (i.e., SMS, online, or paper) method when using diaries in sexual behaviour research. The researchers found that $51 \%$ of participants preferred the online platform, and while 3.9\% of the SMS and 3.1\% of paper diaries were incomplete, only $0.5 \%$ of the online diaries were incomplete. The researchers concluded that online data collection for diaries was the most preferable for participants and was also more likely to lead to completed entries.

The remainder of this section examines blogs as data sources in research studies that are limited to solicited blogs (i.e., voluntarily written for research purposes). The majority of the issues outlined (i.e., advantages, disadvantages, ethical issues, data management) relates to researcher-driven online diary blogs only.

To date there have been very few psychological studies using online solicited diary blogs as a methodological tool for data collection in the gaming studies field. A study by Lewis and Griffiths (2011) utilized this method with female casual gamers (along with other qualitative methods of data collection for a comprehensive understanding of participants' motivations and experiences). The design in the study was innovative because it diverged from traditional pen-paper diaries and in-person or phone based interview formats. It comprised: (i) an introductory e-interview, (ii) a four-week online-focus-group that included solicited diary blogging and forum discussions, and (iii) an exit e-interview. All data (interviews and online focus group discussions) were conducted over a six-week period.

The online focus group lasted four weeks and commenced after introductory e-interviews were completed. The focus group was created and hosted on the blogging and forum platform Ning.com and was limited to invited participants. All content was private, so not discoverable by search engines like Google. Participants created profiles with avatars and were instructed to write diary blog entries daily. They were asked to reflect on game play, score, and motivation, and encouraged to focus on emotions when writing. The online structure of the focus group allowed for discussion in two ways. Firstly, participants were able to read and comment on the blog entries of others. Secondly, participants created and responded to discussion topics posted in the forum area. The researchers posted several topics concerning gaming, gender and technology from current literature, and participants started discussions on topics of their choosing. Data collected from online blog diaries can be analysed both qualitatively (e.g., thematic analysis of the text) and (to some extent) quantitatively including the total number of (i) posts made by the group, (ii) posts made by the individual members, (iii) distinct topic discussions, (iv) discussion topics started by the researcher (and the number of replies), and (v) discussion topics started by the participants (and the number of replies). 
The asynchronous nature of all discussions in the study allowed the participants to respond and participate at their leisure. Ethical issues around consent, privacy, anonymity, withdrawal from the study, and debriefing were handled effectively using email and by posting all relevant study information, and participant rights on the Ning.com site. Furthermore, since the content of the diary/ blog entries were already in text format, no transcription was necessary.

In an effort to control for reflexivity bias, the data were divided into two groups: researcher-led topics from the interviews and discussion forum and participant-led topics from the diaries and discussion forum. Also of note is that the participants were far more informed about game genres, gaming culture, and technical issues around gaming than the researcher. Similar to participatory research schemes (Park, 2001), the participants were experts and were able to introduce new topics of conversation to the study via the online diary blogs.

There were limitations associated with data collection because the online solicited diary blog and online focus groups were new methods for the female gamers, and may not have been ideal formats for sharing and discussion. Indeed, two gamers left the study early on citing an inability to use the 'blogging' tool. In addition, three gamers mentioned experiencing some difficulty in self-expression with the online blog format at the exit e-interview. While these considerations will require adjustments to the method if used in the future, overall the gamers shared a positive view of the format and made comments that implied the online and anonymous nature allowed for greater convenience and self-disclosure (Tidwell \& Walther, 2002). A summary of advantages and disadvantages of using solicited blogs as a methodological tool for data collection are briefly outlined in Table 1 .

Table 1

Advantages versus disadvantages of using solicited blogs as a methodological tool for data collection

\begin{tabular}{ll}
\hline \multicolumn{1}{c}{ Advantages } & \multicolumn{1}{c}{ Disadvantages } \\
\hline $\begin{array}{l}\text { Ease of use for researchers in terms } \\
\text { of software set-up and integrating } \\
\text { participants online. }\end{array}$ & $\begin{array}{l}\text { Blogs require some technical ability, so } \\
\text { it may exclude participants who are less } \\
\text { comfortable with online formats. }\end{array}$ \\
\hline $\begin{array}{l}\text { Self-report format eliminates need for } \\
\text { transcription and the online platform } \\
\text { allows for immediate and continuous }\end{array}$ & $\begin{array}{l}\text { Potential data loss when creating an } \\
\text { entry and losing the content before it } \\
\text { is published or if participants chose to } \\
\text { access to data. }\end{array}$ \\
$\begin{array}{ll}\text { Convenience and flexibility of the } \\
\text { platform in terms of participants' time } \\
\text { management and commitment to data } \\
\text { entry as blogs can be accessed at any }\end{array}$ & $\begin{array}{l}\text { The potential for "digital fatigue" (Kaun, } \\
\text { participants who might lose motivation } \\
\text { inme via the Internet. }\end{array}$ \\
\hline
\end{tabular}




\begin{tabular}{|c|c|}
\hline Advantages & Disadvantages \\
\hline $\begin{array}{l}\text { Ability to control participant anonymity } \\
\text { through the use of alias identities } \\
\text { (usernames, generic email addresses). }\end{array}$ & $\begin{array}{l}\text { Reduced researcher control over the } \\
\text { research environment and ensuring } \\
\text { participant identity (Kraut et al., 2004). }\end{array}$ \\
\hline $\begin{array}{l}\text { Privacy controls in most blogging } \\
\text { software allow for varying levels of } \\
\text { privacy, so either the researcher or the } \\
\text { participant can control who sees what } \\
\text { content. Participants can share with the } \\
\text { group or only with the researcher. }\end{array}$ & $\begin{array}{l}\text { Content is solicited for research and is } \\
\text { written with an understanding that it } \\
\text { will be analysed. Therefore, the level of } \\
\text { self-disclosure and the topics chosen } \\
\text { may be highly regulated by participants. }\end{array}$ \\
\hline
\end{tabular}

\section{ETHICAL ISSUES IN ONLINE FORUM AND ONLINE SOLICITED BLOG DATA COLLECTION}

In online research, the lines have become blurred between 'public' and 'private' spaces (Griffiths, 2010; Griffiths \& Whitty, 2010). It could perhaps be argued that data collected from online blogs or forums are "public" unless specifically designated and/or signposted by its users as "private". Rather than the physicality of the situation, some social scientists may argue that it is the participants' and/or users' perceptions that define whether the domain is viewed as public or private (Wood \& Griffiths, 2007). If the researcher is involved in online participant observation, the issue of privacy may become even more complicated. It has been the practice of the authors in their gaming research to make other blog and/or forum users aware that they are collecting data unless there is good reason to assume that this would adversely affect the quality and/or the type of data collected. Arguably the most important issues regarding the ethics of collecting online gaming data from blogs and forums include informed consent, deception, private versus public space, lurking, and data use and ownership (e.g., Buchanan \& Williams, 2010; Ess \& Jones, 2004; Maczewski, Storey, and Hoskins, 2004; Sixsmith \& Murray, 2001; Whitty, 2004b). These are now briefly examined in specific relation to online data collection via forums and solicited blogs.

\section{Informed consent}

The issue of informed consent in research participation is considered one of the 'bedrocks' of research ethics. However, there is a debate about whether such consent is needed if the data are collected from public online forums or blogs (Sveningsson, 2004). The present authors' view is that online forum and blog data provided by gamers and gamblers are essentially secondary data and therefore informed consent is not an issue in the traditional sense. Issues such as withdrawal of data are not really a problem as gamers and gamblers have usually proactively posted on a gaming blog or forum (and by proxy) consented to sharing their 'data' with anybody who happens to come across that particular 
webpage. Informed consent requires researchers to be honest and open about the aims of their research and how they are going to utilize the data they collect. If the researcher is participating in the research process itself (i.e., contributing to the forum or blog) they should make their researcher status known to others in the group as the participants are then aware that anything they write might be used for research purposes.

In some instances, online forums are moderated. Here, it is appropriate for the researcher to contact the moderators in advance of participating in the forum under study. This is akin to contacting the head of an organisation and seeking permission to collect data from its members, employees, clients, patients, etc. Research examining 'sensitive' issues (such as gambling and gaming addictions) has the potential to cause distress for a participant - even when there is no malice intended from the researcher. Griffiths and Whitty (2010) in their review of ethical issues in online gambling research advise that safeguards need to be put into place to ensure online gamblers have access to professional help if for some reason the data collection process causes any psychological distress.

For some, using data from publicly accessible online forums or diary blogs has the potential to interfere with the validity of the research process. While some researchers criticise the use of forum participants' data for research purposes (King, 1996), the act of contacting participants to ask for consent about using their posts and/or blogs in online websites may interfere with the participants' desire to post on the forum in the future, and may potentially damage the dynamics of the online forum. Ultimately, it is the researcher's responsibility to decide whether they should ask for consent to use the information and/or do everything they reasonably can to protect the identity of the participants. The authors' experience with gamblers and gamers suggests this is not usually a problem for this particular group.

\section{Deception}

The use of deception is one of the most serious ethical concerns for researchers who collect their data online. Whitty (2004) contends that it is ethically unacceptable to pose as another person in the category group under investigation (e.g., an online gambler or gamer) rather than as a researcher, especially as there are usually more ethical ways to collect such data. Therefore, practice of letting participants know that a researcher is present in an online forum is paramount from an ethical perspective.

\section{Lurking}

The issue of 'lurking' (i.e., being a passive observer in an online space) is a particular issue for those researchers collecting data from online forums and blogs. Respect for a research participant's right to privacy is a basic ethical requirement. In general, the basic rule of thumb is that researchers should only observe 
people in a situation where they would ordinarily expect to be observed, such as a public space (Griffiths \& Whitty, 2010). However, in online situations these boundaries can become blurred (Wood \& Griffiths, 2007). Researchers need to consider if they have the right to lurk in gaming online forums and blogs in order to learn more about the group under examination. Griffiths and Whitty (2010) also note that there may be some topics (particularly concerning research on sexual activity) where it is ethically desirable for researchers to use their institutions' servers to lurk in online sites containing potentially illegal material.

\section{Private versus public space}

As mentioned earlier in this paper, a concern that is arguably more salient to online (compared to offline) research is the perception of space as 'public' or 'private'. Researchers have noted that private interactions can (and do) take place in public spaces (Mann \& Stewart, 2000). Although online interactions have the potential to be observed by many people, those online may not perceive their interactions as 'public' because peoples' perceptions of 'public' are often based on events in the offline world (i.e., a public space is more obvious in offline settings). Furthermore, Sharf (1999) has also noted that "despite widely announced admonitions concerning the potential for public exposure, there exists the paradox that writing to others via e-mail often feels like a private or, in the case of an online group, quasi-private act" (p. 246). Researchers should acknowledge that there are different spaces and places online, and that the perception of 'public' and 'private' may change depending upon the type of online space. For example, a chat room or an online forum might be deemed a more public space than (say) email. However, the demarcations are not always clear-cut or obvious. For instance, Griffiths and Whitty (2010) asked whether an online self-help support group for gamblers that can be accessed by anyone online was a public or private space?

If, as we believe, most online spaces are public unless deemed otherwise, researchers must acknowledge that the anonymity they afford can give the illusion to the users that they are private spaces. Therefore, Griffiths and Whitty (2010) have posed the question of whether researchers should ethically take advantage of online users' false sense of privacy and security? They also ask whether it is ethically justifiable to lurk in online gambling sites and collect data without the knowledge or consent of the individuals who inhabit these sites? It is assumed that in online spaces such as forums or blogs, people are not aware of others' presence unless they make themselves explicitly known to them, at which point the situation becomes public, unless those being studied are under the impression that they are in a private correspondence with the researcher (Wood \& Griffiths, 2007). In other words, Griffiths and Whitty argue that it is the perceptions of the participant that define the domain as public or private, rather than the physicality of the situation. Furthermore, Whitty (2004) rightly notes that although online interactions arguably take place in public spaces, this does not 
mean that the intended audience is a researcher. Ultimately, researchers need to empathise with the participant and view the online space from their perspective.

\section{Data use and ownership}

Issues in data ownership occur when researchers appropriate the material that is in online forums and blogs for research purposes. Deciding the ownership of communications that are collected online can be challenging. As suggested by Sixsmith and Murray (2001), an important question to address is to whom do the posts belong? Do they belong to the writer of the post or blog, the electronic group (i.e., online community), or any online observer (including researchers)? Although it is beyond the remit of this paper to answer these questions, there are some recommended strategies that can be adopted by researchers to protect participants' integrity when collecting data online. These include:

- Confirming if the online forum or blog includes regulations about using participants' posts for research purposes.

- Removing identifiers such as nicknames or pseudonyms. Bechar-Israeli (1995) surveyed 278 IRC users about the use of nickname choices and found that only $7 \%$ used some part of their legal name but that $45 \%$ used a nickname that was somehow related to them (e.g., age, gender, location, etc.). Bechar-Israeli (1995) also noted that individuals usually created one persona online and used it consistently. Given that reputation is usually created around nicknames (Lawson, 2004; Kraut et al., 2004), this means that the researchers should do all they reasonably can to protect both individuals' online and offline identity. This issue has become even more important as many online forums and blogs allow users to post using Facebook and/or Wordpress accounts. These accounts may subsequently reveal a participant's real life identity and facilitate the potential that they could be traced.

- Being aware that digital data are easily stored and replicated. Simply giving participants' pseudonyms may not be enough protection as search engines can easily trace the source of a verbatim piece of text. Whether or not a researcher should quote from an online conversation needs to make careful consideration. For this reason, there could be a case for the researchers make subtle modifications (e.g., correcting the person's grammar) without changing the sense of the original posts or blogs. However, such changes might (in some situations) lead to problems with validity and reliability.

- Removing any other identifiers that may provide information that allows identification of the post or blog source (such as the names of the forum or blog used). However, this may be impractical if the researcher has recruited the participants in the online forum or blog site itself (i.e., the researcher may have already left permanent information that is easy to track). The 
desire to protect the identity of participants in online forums and blogs can be challenging as not specifying the forums or blogs where the data were taken from and slightly modifying the text may then interfere with the validity, replicability, and research reliability (Sixsmith \& Murray, 2001).

\section{Conclusion}

The aim of this paper was to briefly overview two relatively new ways of collecting data online, and to suggest that these would be particularly advantageous for researchers who work in the game studies field (in studying gamblers and video game players). More specifically, it outlined the advantages and disadvantages of collecting data from online forums and online solicited diary blogs, mainly based on the authors' own published research in the area of gambling and gaming. Although online data collection may raise concerns about the research participants' integrity and the quality of the data collected, it is concluded that these new innovative research methods can provide new insights unavailable to other online data collection methods.

\section{REFERENCES}

Bechar-Israeli, H. (1995). From <Bonehead $>$ to $<$ cLoNehEAd $>$ : Nicknames, play and identity on Internet relay chat. Journal of Computer-Mediated Communication, 1(2). Available at: http://209.130.1.169/jcmc/voll/issue2/ bechar.html

Buchanan, T. (2000). Potential of the Internet for personality research. In M. H. Birnbaum, (Ed.), Psychological experiments on the Internet (pp. 121-140). San Diego: Academic Press.

Buchanan, T. (2007). Personality testing on the Internet: What we know, and what we do not. In A. N., Joinson, K. Y. A., McKenna, T. Postmes, \& U.-R. Reips, (Eds.), The Oxford Handbook of Internet Psychology (pp. 447-459). Oxford: Oxford University Press.

Buchanan, T., \& Williams, J. E. (2010). Ethical issues in psychological research on the Internet. In S. D. Gosling \& J. A. Johnson (Eds.), Advanced Methods for Conducting Online Behavioral Research (pp. 255-271). Washington, DC: American Psychological Association.

Chappell, D., Eatough, V. E., Davies, M. N. O., \& Griffiths, M. D. (2006). EverQuest - It's just a computer game right? An interpretative phenomenological analysis of online gaming addiction International Journal of Mental Health and Addiction, 4, 205-216.

Cohen, J. D., Leviton, L. C., Isaacson, N., Tallia, A. F., \& Crabtree, B. F. (2006). Online diaries for qualitative evaluation, American Journal of Evaluation, $27,163-184$. 
Crystal, D. (2005, February). The scope of Internet linguistics. In American Association for the Advancement of Science Conference. Available at: http:// www.davidcrystal.com/DC_articles/Internet2.pdf

Davies, R. N. (1999). Web-based administration of a personality questionnaire: Comparison with traditional methods. Behavior Research Methods, Instruments, and Computers, 31, 572-577.

Edmunds, H. (1999). The focus group research handbook. Lincolnwood, IL: NTC Business Books/Contemporary Publishing.

Enoch, Y., \& Grossman, R. (2010). Blogs of Israeli and Danish backpackers to India. Annals of Tourism Research, 37, 520-536.

Ess, C., \& Jones, S. (2004). Ethical decision making and Internet research: Recommendations from the AoIR Ethics Working Committee. In E. A. Buchanan (Ed.), Readings in Virtual Research Ethics: Issues and Controversies (pp. 27-44). Hershey, USA: Idea Group Inc.

Eysenbach, G., \& Till, J. E. (2001). Ethical issues in qualitative research on internet communities. British Medical Journal, 323, 1103-1105.

Fullwood, C., Sheehan, N., \& Nicholls, W. (2009). Blog function revisited: A content analysis of MySpace blogs. CyberPsychology and Behavior, 12, 685-689.

Geertz, C. (1973). The interpretation of cultures: Selected essays. London: Fontana Press.

Griffiths, M. D. (2010). The use of online methodologies in data collection for gambling and gaming addictions. International Journal of Mental Health and Addiction, 8, 8-20.

Griffiths, M. D., \& Whitty, M. W. (2010). Online behavioural tracking in Internet gambling research: Ethical and methodological issues. International Journal of Internet Research Ethics, 3, 104-117.

Herring, S. C., Scheidt, L. A., Bonus, S., \& Wright, E. (2005). Weblogs as a bridging genre. Information, Technology and People, 18, 142-171.

Herring, S. C., Scheidt, L. A., Kouper, I., \& Wright, E. (2006). A longitudinal content analysis of weblogs: 2003-2004. In M. Tremayne (Ed.), Blogging, Citizenship, and the Future of Media (pp. 1-18). London: Routledge.

Hine, C. (Ed.). (2005). Virtual methods. Issues in social research on the Internet. Oxford, UK: Berg.

Hine, C. (2000). Virtual ethnography. London: Sage.

Hookway, N. (2008). 'Entering the blogosphere': Some strategies for using blogs in social research. Qualitative Research, 8, 91-113.

Howard, G. S. (1994). Why do people say nasty things about self-reports? Journal of Organizational Behavior, 15, 399-404.

Im, E. O., Liu, Y., Dormire, S., \& Chee, W. (2008). Menopausal symptom experience: An online forum study. Journal of Advanced Nursing, 62, 541-550.

Im, E. O., \& Chee, W. (2006). An online forum as a qualitative research method: Practical issues. Nursing Research, 55, 267-273. 
Jankowski, N. W., \& van Selm, M. (2005). Methodological concerns and innovations in Internet research. In C. Hine (Ed.), Virtual methods. Issues on social research on the Internet (pp. 199-208). Oxford: Berg.

Joinson, A. N., Paine, C., Buchanan, T., \& Reips, U.-D. (2008). Measuring selfdisclosure online: Blurring and non-response to sensitive items in web-based surveys. Computers in Human Behavior, 24, 2158-2171.

King, S. A. (1996). Researching Internet communities: Proposed ethical guidelines for the reporting of results. Information Society, 12(11), 119-127.

Kaun A. (2010). Open-ended online diaries: Capturing life as it is narrated. International Journal of Qualitative Methods, 9(2), 133-148.

Kinkus, J. F. (2002). Science and technology resources on the Internet: Computer security. Issues in Science and Technology Librarianship, 36. Available at: http:// www.istl.org/02-fall/internet.html

Kozinets, R. V. (2010). Netnography. Doing ethnographic Research Online. Sage: London.

Krantz, J. H. (2000). Tell me, what did you see? The stimulus on computers. Behavior Research Methods Instruments and Computers, 32, 221-229.

Kraut, R., Olson, J., Banaji, M., Bruckman, A., Cohen, J., \& Couper, M. (2004). Psychological research online: Report of board of scientific affairs' advisory group on the conduct of research on the Internet. American Psychologist, 59(2), 105-117.

Lawson, D. (2004). Blurring the boundaries: Ethical considerations for online research using synchronous CMC forums. In E. A. Buchanan (Ed.), Reading in Virtual Research Ethics. Issues and Controversies (pp. 80-100). Information Science Publishing: London.

Lewis, A., \& Griffiths, M. D. (2011). Confronting gender representation: A qualitative study of the experiences and motivations of female casual-gamers. Aloma: Revista de Psicologia, Ciències de l'Educació i de l'Esport, 28, 245-272.

Ley, D. (1988). Interpretive social research in the inner city. In J. Eyles (Ed.), Research in human geography (pp. 121-138). Oxford: Blackwell.

Lim, M., Sacks-Davis, R., Aitken, C., Hocking, J., \& Hellard, M. (2010). Randomised controlled trial of paper, online and SMS diaries for collecting sexual behaviour information from young people. Journal of Epidemiological Community Health, $64,885-889$.

Maczewski, M., Storey, M., \& Hoskins, M. (2004). Conducting congruent, ethical, qualitative research in Internet-mediated research environment. In E. A. Buchanan (Ed.), Reading in Virtual Research Ethics. Issues and Controversies (pp. 62-77). Information Science Publishing: London.

Mann, C. \& Stewart, F. (2000). Internet Communication and Qualitative Research: A Handbook for Researching Online. London: Sage.

Markham, A. N. (1998). Life online. Researching real experience in virtual space. New York: AltaMira. 
Marra, R. M., Moore, J. L., \& Klimczak, A. K. (2004). Content analysis of online discussion forums: A comparative analysis of protocols. Educational Technology Research and Development, 52(2), 23-40.

Miura, A., \& Yamashita, K. (2007). Psychological and social influences on blog writing: An online survey of blog authors in Japan. Journal of ComputerMediated Communication, 12(4), Article 15. Available at: http://jcmc.indiana. edu/vol12/issue4/miura.html

Ortiz de Gortari, A., Aronnson, K. \& Griffiths, M. D. (2011). Game Transfer Phenomena in video game playing: A qualitative interview study. International Journal of Cyber Behavior, Psychology and Learning, 1(3), 15-33.

Paccagnella, L. (1997). Getting the Seats of Your Pants Dirty: Strategies for Ethnographic Research on Virtual Communities. Journal of ComputerMediated Communication, 3: 0. doi: 10.1111/j.1083-6101.1997.tb00065.x

Papacharissi, Z. (2007). Audiences as media producers: Content analysis of 260 blogs. In Z. Papacharissi (Ed.), Blogging, citizenship, and the future of media (pp. 21-38). New York: Taylor \& Francis.

Park, P. (2001). Knowledge and participatory research. In P. Reason \& H. Bradbury, (Eds.), Handbook of action research: Participative inquiry and practice (pp. 81-90). London: Sage Publications.

Parke, A., \& Griffiths, M. D. (2011). Poker gambling virtual communities: The use of Computer-Mediated Communication to develop cognitive poker gambling skills. International Journal of Cyber Behavior, Psychology and Learning, 1(2), 31-44.

Qian, H., \& Scott, C. R. (2007). Anonymity and self-disclosure on weblogs. Journal of Computer-Mediated Communication, 12(4), Article 14. Available at: http:// jcmc.indiana.edu/vol12/issue4/qian.html

Reips, U.-D. (2002). Standards for Internet-based experimenting. Experimental Psychology, 49, 243-256.

Rezabek, R. J. (2000). Online focus groups: Electronic discussions for research. Forum: Qualitative Social Research (Sozialforschung), 1(1), 18.

Schmidt, W. C. (2007). Technical considerations when implementing online research. In A. N. Joinson, K. Y. A. McKenna, T. Postmes, \& U.-D. Reips (Eds.), The Oxford Handbook of Internet Psychology (pp. 461-472). Oxford: Oxford University.

Schofield, W. J. (1993). Increasing the generalizability of qualitative research. In M. Hammersley (Ed.), Social research. Philosophy, politics and practice (pp. 200-225). London: Sage.

Schultz, T. (2000). Mass media and the concept of interactivity: An exploratory study of online forums and reader email. Media, Culture \& Society, 22(2), 205-221.

Serfaty, V. (2004). The Mirror and the Veil: An Overview of American Online Diaries and Blogs. New York: Rodopi. 
Sharf, B. F. (1999). Beyond netiquette: The ethics of doing naturalistic discourse research on the Internet. In S. Jones (Ed.), Doing Internet Research: Critical Issues and Methods for Examining the Net (pp. 243-256). London: Sage.

Sixsmith, J., \& Murray, C. D. (2001). Ethical Issues in the documentary data analysis of Internet post and archives. Qualitative Health Research, 11, 423-432. Sveningsson, M. (2004). Ethics in Internet ethnography. In E. Buchanan (Ed.), Readings in Virtual Research Ethics: Issues and Controversies (pp. 45-61). Hershey, USA: Idea Group Inc.

Taylor, T. L. (2006). Play between worlds. Exploring online game culture. Cambridge, MA: MIT.

Technorati Media (2011). State of the Blogosphere 2011. Technorati.com. Retrieved 25 February 2012. From http://technorati.com/social-media/feature/ state-of-theblogosphere-2011/

Thurlow, C. (2001). The Internet and language. In R. Mesthrie \& R. Asher (Eds.). (2001). Concise Encyclopedia of Sociolinguistics (pp. 287-289). London: Pergamon.

Tidwell, L. C., \& Walther, J. B. (2002). Computer-mediated communication effects on disclosure, impressions, and interpersonal evaluations: Getting to know one another a bit at a time. Human Communication Research, 28(3), 317-348.

Turkle, S. (1995). Life on the screen. Identity in the age of the Internet. New York: Simon \& Schuster.

Whitty, M. T. (2004a). Cyber-flirting: An examination of men's and women's flirting behaviour both offline and on the Internet. Behaviour Change, 21, $115-126$.

Whitty, M. T. (2004b). Peering into online bedroom windows: Considering the ethical implications of investigating Internet relationships and sexuality. In E. A. Buchanan, (Ed.), Readings in Virtual Research Ethics: Issues and Controversies (pp. 203-218). Hershey, USA: Idea Group Inc.

Wilkinson, S. (1988). The role of reflexivity in feminist psychology. Women's Studies International Forum, 11, 493-502.

Williams, J. B., \& Jacobs, J. (2004). Exploring the use of blogs as learning spaces in the higher education sector. Australasian Journal of Educational Technology, 20, 232-247.

Wood, R. T. A. \& Griffiths, M. D. (2007). Online data collection from gamblers: Methodological issues. International Journal of Mental Health and Addiction, 5, 151-163.

Wood, R. T. A., Griffiths, M. D., \& Eatough, V. (2004). Online data collection from videogame players: Methodological issues. CyberPsychology and Behavior, 7, 511-518.

Wysocki, D. K. (1998). Let your fingers to do the talking: Sex on an adult chat-line. Sexualities, 1, 425-452. 